\title{
Virola theiodora como alucinógena e tóxica
}

\author{
J. G. Soares MaIa (*) \\ William A. Rodrigues (") \\ Instituto Nacional de Pesquisas \\ da Amazônia
}

\begin{abstract}
SINOPSE
Comprova-se por análise cromatográfica (CCD) e espectrometrias no infravermelho (IV) e no ultravioleta (UV) o duplo emprego da casca de Virola theiodora (Spruce ex Benth.) Warb. (Myristicaceae) no preparo de rapé alucinogênico e envenenamento de flechas, pelos índios Yomanê, da regiăo do rio Tototobi, Território Federal de Roraima.
\end{abstract}

\section{INTRODUÇÃo}

Visa o presente trabalho reconhecer e comprovar quimicamente por comparação com fragmentos de herbário a semelhança de substâncias psicoativas e tóxicas (triptaminas) em rapé e flechas envenenadas, preparadas pelos indios Yomanê da região do rio Tototobi. Território de Roraima, com as que existem na casca de Virola theiodora (Spruce ex Benth.) Warb. (Miristicácea).

Schultes (1954, 1969a, 1969b e 1970), Schultes \& Holmstedt (1968 e 1971), Agurell et alii (1969), Prance (1970, 1972a e 1972b) e outros que discutem amplamente o costume indígena de se usar a resina da casca de algumas espécies de Virola para fins alucinogênicos e mesmo envenenamento de flechas, informam estar este hábito arraigado exclusivamente aos índios que habitam vasta área do noroeste amazônico, incluindo o Brasil e as regiões adjacentes da Colômbia e Venezuela.

Schultes (1970) reconhece pelo menos três espécies de Virola como as mais procuradas pelos índios: $V$. theiodora no Brasil e Venezuela, V. calophylla Warb e V. calophylloidea Markf. na Colômbia, sendo, no entanto, a primeira a mais importante pelo seu duplo emprego, isto é, como psicotrópico e como veneno de flechas.

Schultes \& Holmstedt (1971) e Prance (1970) que testemunharam o preparo de flechas envenenadas entre os índios Waiká do rio Tototobi, observaram que somente $V$. theiodora é usada, embora Biocca citado por Schultes \& Holmstedt (1971) aponte a prática da mistura de curare à resina de Virola por outros grupos da mesma tribo no preparo dessas flechas. Prance (1970 e 1972b) observa que os princípios ativos que poderiam produzir efeitos tóxicos nas flechas ainda não estão bem definidos e que sua ação é bem mais lenta que a do curare e a do veneno obtido de outras plantas como a morácea Naucleopsis mellobarretoi. C. C. Berg. Schultes (1969b) aponta que a resina pura de $V$. theiodora chega a conter $8 \%$ de 5 -Metoxi-N, $\mathrm{N}$ - dimetiltriptamina, um psicoativo altamente eficaz.

Existem diferentes tipos de rapé, variando de acordo com o modo de preparo. Há os que são usados sem mistura e outros onde entram adicionantes como o pó da folha de Justicia pectoralis Jacq. (Acantácea) como aromatizante ou as cinzas de Elizabetha princips Schomb. ex Bth. (Leguminosa) e provavelmente outras plantas como citam Schultes (1969a e 1970) e Prance (1972a e 1972b), com a finalidade provavelmente de reduzir o seu efeito tóxico.

Agurell et alii (1969) analisando duas amostras de rapé de procedência e modo de preparo diferentes, verificaram que a concentração de alcalóides no rapé baixa de $1 / 10 \mathrm{em}$ relação ao puro, ou seja, aquele obtido unica-

(*) - Bolsista do Conselho Nacional de Pesquisas 
mente de $V$. theiodora, e que este último provou conter nada menos que $11 \%$ de alcalóides.

V. theiodora é conhecida pelos índios Yomanê como yakohana ou yakohana-hi. Outros nomes citados na literatura para a mesma espécie e espécies afins ( $V$. elongata $=V$. cuspidata e V. rufula) são: nyakwana, jakuana, epená, paricá, shomiá, machfara-a, tchkiana, ucufe-ey, ra-se-nê-mee, tsu-nem e yakee.

\section{MATERIAL E MÉTODOS}

Usaram-se para análise nos laboratórios de química de produtos naturais do INPA, 5 pontas de flechas empregnadas com resina e cerca de $5 \mathrm{~g}$ de um pó avermelhado, ambos de origem vegetal, colhidos dos índios Yomanê da região do rio Tototobi, no Território $\mathrm{Fe}$ - deral de Roraima, e fragmentos de casca de vários espécimes de Virola incorporados no herbário do INPA: V. theiodora: Prance, 9607 (INPA, 26744); Prance, 10125 (INPA, 27257); Prance, 20025 (INPA, N.Y.). V. calophylla (A.DC.) Warb.: INPA, 42214. V. rufula Warb.: INPA, 42227. V. caducifolia W. Rodr. n. sp.: INPA, 42232. V. venosa (Bth.) Warb.: INPA, 42241.

Elaboraram-se extratos benzênicos e etanólicos da resina extraída de cada uma das pontas de flechas, do pó e dos fragmentos de casca dos espécimes de Virola.

Compararam-se por cromatografia em camada delgada (CCD), espectrometria no infravermelho (IV) e espectrometria no ultravio. leta (UV).

\section{Resultados}

Quadro 1. CCD dos extratos benzênicos da resina das flechas e rapé dos índios Yomanê e de fragmentos de casca de V. theiodora: Prance, 9607, 10125 e 20025 .

$\mathrm{SiO}_{2}$, benzeno - acetona, $8: 2$

\begin{tabular}{|c|c|c|}
\hline $\begin{array}{c}\text { V. theiodora } \\
\text { Rf }\end{array}$ & $\begin{array}{c}\text { resina das flechas } \\
\text { Rf }\end{array}$ & $\begin{array}{l}\text { rapé (ou pó) } \\
\text { Rf }\end{array}$ \\
\hline $\begin{array}{l}0,82 \text { (I }{ }^{\prime} \text {, vapores) } \\
0,72 \text { (UV, azul) } \\
0,65 \text { (I }{ }^{\prime} \text {, vapores) } \\
0,42 \text { (I }{ }^{\prime} \text {, vapores) } \\
0,00 \text { a } 0,36 \quad\left(I_{2} \text { ' }\right. \\
\text { vapores) }\end{array}$ & $\begin{array}{l}0,82\left(I_{2}, \text { vapores) }\right. \\
0,72 \text { (UV, azul) } \\
0,65 \text { (I }{ }^{\prime} \text {, vapores) } \\
0,42 \quad\left(1^{\prime} \text {, vapores) }\right. \\
0,00 \text { a } 0,36 \quad\left(I_{2}{ }^{\prime}\right. \\
\text { vapores) }\end{array}$ & $\begin{array}{l}0,82 \text { (1 }{ }_{2}^{\prime} \text { vapores) } \\
0,72 \text { (ƯV, azul) } \\
0,65 \text { (1 }{ }^{\prime} \text {, vapores) } \\
0,42 \quad\left(1_{2}^{\prime} \text { vapores) }\right. \\
0,00 \text { a } 0,36 \quad\left(1_{2},\right. \\
\text { vapores) }\end{array}$ \\
\hline
\end{tabular}

Quadro 2. CCD dos extratos etanólicos da resina das flechas e rapé dos índios Yomanê e de fragmentos de casca de V. theiodora: Prance, 9607, 10125 e 20025 .

$\mathrm{SiO}_{2}$, metanol.

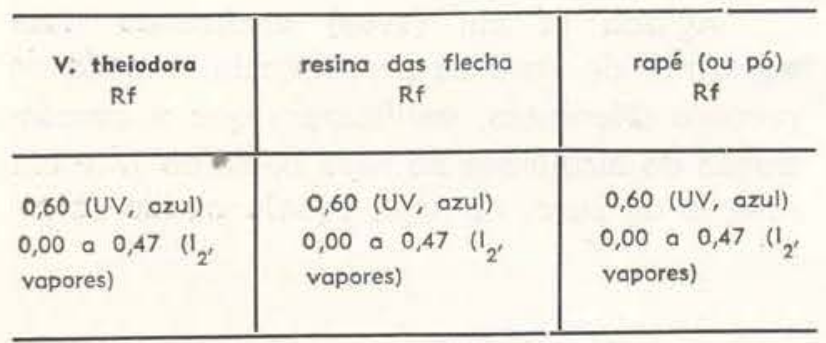

Quadro 3. Espectros no IV dos extratos benzênicos e etanólicos da resina das flechas e rapé dos índios Yomanê e de fragmentos de casca de V. theiodora: Prance, 9607, 10125 e 20025.
Quadro 4. Espectros no UV dos extratos benzênicos e etanólicos da resina das flechas e rapé dos índios Yomanê e de fragmentos de casca de V. theiodora: Prance, 9607, 10125 e 20025 . 


\section{Conclusões}

Os extratos benzênicos e etanólicos da resina extraída das pontas das flechas e rapé dos índios Yomanê e dos fragmentos de casca de V. theiodora (Prance, 9607, 10125 e 20025) apresentaram o mesmo desenvolvimento em placas cromatográficas de sílicagel G (Merck) (quadros 1 e 2), assim como seus espectros no IV e no UV mostraram ser superponíveis (quadros 3 e 4). Os dados obtidos no UV foram idênticos aos de Agurell et alii (1969).

Também foi verificado que os extratos elaborados mostraram a ausência de possíveis misturas com outras espécies.

\section{SUMMARY}

In this paper it is confirmed by thin layer chromatography analysis (TLC) and infrared (IR) and ultraviolet (UV) spectroscopy the double use of the bark from the myristicaceous Virola theiodora (Spruce ex Benth.) Warb. in the hallucinogenic snuff and arrow poison prepared by indians called Yomanê from Tototobi river at the Brazilian Territory of Roraima.

\section{BIBLIOGRAFIA CITADA}

AgURELL, S. ET ALII

1969 - Alkaloids in Certain Species of Virola and other South American Plants of Ethnopharmacologic interest. A ct a Chem. Scand., 23(3):903-916.
Prance, G. T.

1970 - Notes on the use of plant Hallucino. gens in Amazonian Brazil. Econ. Bot., 24(1):62-68

1972a - Ethriobotanical notes from Amazonian Brazil. Econ. Bot., 26(3):221-237, 14 ilust.

1972b- An Ethnobotanical comparison of four Tribes of Amazonian Indians. Acta Amazonica, 2(2):7-27, 17 ilust.

SCHULTES, R. E.

1954 - A new Narcotic Snuff from the Northwest Amazon. Bot. Mus, Leafl. Harv. Univ., 16:241-260.

1969a- The Plant Kingdon and Hallucinogens. Part I. Bull. of. Narcot., 22(1):1-56.

$1969 \mathrm{~b}$ - De Plantis Toxicariis e Mundo Novo Tropicale Commentationes. V. - Virola as an Orally Administered Hallucinogen. Bot. Mus. Leafl. Harv. Univ., 22(6) : 229-240.

1970 - The New World Indians and their Hallucinogenic Plants. Morris Arbor. Bull., 21(1):3-14.

SCHULtes, R. E. \& HOLMSTEDT, B.

1968 - The Vegetal Ingredients of the Myristicaceous Snuffs of the Northwest Amazon. Rhodora, 70:113-156.

1971 - De Plantis Toxicariis e Mundo Novo Tropicale Commentationes. VIII. Miscelleneous Notes on Myristicaceous Plants of South America. Lloydia, 34 (1):61-78, 7 ilust. 